\title{
Extracorporeal Photopheresis: Scientific and Technical Considerations for Improving Clinical Management of Patients
}

Frédéric Garban $^{1-4 *}$, Caroline Makowski², Sylvain Carras ${ }^{2}$, Philippe Drillat ${ }^{2}$, Remy Gressin ${ }^{1}$, Jean Yves Cahn ${ }^{1,3,4}$ and David Laurin $^{2,3}$

${ }^{1} \mathrm{CHU}$ Grenoble, Department of Hematology, France

${ }^{2}$ Établissement Français du Sang Rhône Alpes, La Tronche, France, La Tronche, France

${ }^{3}$ CNRS UMR 5525, TheREx, France

${ }^{4}$ Joseph Fourier University, France

\begin{abstract}
Extracorporeal photopheresis or chemophototherapy (ECP) is a current therapy and concept that has demonstrated clinical efficacy in the treatment of acute and chronic graft versus host disease (GVHD), Sezary syndrome or cutaneous T-cell lymphoma (CTCL) and organ transplant rejection. Patient inclusion in ECP protocols increases due to the diffusion of technical progress but has to be explored regarding various schedules and processes. ECP mechanisms of action are still unclear despite evident implication of a complex cascade beginning from the apoptosis of the various cell types collected and exposed to the process that is followed by an immunomodulation via antigen presentation. Exploration of the mechanisms in animal models has many limits that weakness human clinical link. Beside major indications, the barrier to ECP treatment extension is the absence of randomized trials in comparison to alternative therapies. The cost of ECP treatment is also a limitation and has to be evaluated relative to other strategies. Nevertheless, the efficacy and the absence of major side effects deserve attention, mainly for the extension of the ECP treatment in clinical trials as new therapeutic line.
\end{abstract}

Keywords: GVHD; Photopheresis; T-cell lymphoma; Apheresis; Cell therapy

\section{Introduction}

Starting at the end of 90's, and derived from PUVA therapy, arose the concept of modulation of inappropriate immune conflicts by direct action of UVA on immunocompetent cells (lymphocytes, antigen processing cells). After the inactivation of T-cells in vitro and ex vivo, was demonstrated, the development step-by-step aimed to process large amounts of the so-called peripheral mononuclear cells. Harvested by apheresis followed by psoralen and UVA treatment cells are reinjected into the patient. The process is called extracorporeal photopheresis or chemophototherapy (ECP). First systemic indications were Sezary syndrome [1], graft versus host disease (GVHD) and solid organ transplantation $[2,3]$. Today, ECP clinical relevance is demonstrated for three major indications: chronic GVHD, Sezary T-cell lymphoma and cardiac graft rejection.

Confirmed clinical results led research to two paths. The main path obviously involves the mechanisms of action of the ECP on the immune system; and the other involves the simplification of the technical aspects of the treatment. On the other hand, clinical trials almost only evaluated on retrospective studies, showed interesting results for various indications from hematology to organ transplantation and other immune disorders. But except the three main historical indications, ECP continues to be a controversial treatment, probably due to the mechanism of action not being identified, the varying photopheresis procedures and treatment schedules, and the difficulty of conducting trials on relatively rare diseases with involvement of clinically heterogeneous organs.

\section{Mechanisms of Action for ECP: From T Lymphocytes Apoptosis to Modulation of Antigen-Presenting Cells}

It is very intriguing that the shared characteristic of the distinct pathologies for which the ECP treatment is a major indication, is the presence of a contingent of T-cells associated with the disorders. Nevertheless the ECP process apparently affects the pathologies in different, even opposite, ways. In cutaneous T-cell lymphoma, an immunostimulatory effect appears predominant whereas an immunosuppressive effect is more likely to be the core benefit of the process in other indications of ECP.

During ECP, the mononuclear cells (not only lymphocytes) are reinfused into the patient while apoptosis is induced through covalent cross-links in DNA. It has long been postulated that the contingent of cells induced to death includes T-cells associated to the pathology treated. Yet only $5-10 \%$ of blood mononuclear cells are exposed to the process (representing less than $1 \%$ of the body total Tlymphocytes) and only a very small number are the neoplastic T-cell clones or even less in case of GVHD because patients are lymphopenic [4]. Considering the delayed clinical responses observed, mechanisms other than the central role of depleting pathogenic T-cell clones may exist. In light of the facts that the standard schedule involves one to two courses weekly for few weeks [5], and that GVHD-treated patients are still able to respond to immune challenges from pathogens or vaccines [6], the key mechanism appears to be an immunomodulation rather than an immunodepletion.

Animal models are powerful tools to develop a hypothesis before undertaking complicated and restrictive explorations in human subjects. However these studies do not allow direct clinical conclusions to be

*Corresponding author: Prof. Fréderic Garban, Établissement Français du Sang Rhône Alpes, 29 avenue maquis du Grésivaudan, F38700 La Tronche, France, Tel: +476424344; E-mail: fgarban@chu-grenoble.fr

Received July 07, 2014; Accepted September 09, 2014; Published September 11,2014

Citation: Garban F, Makowski C, Carras S, Drillat P, Gressin R, et al. (2014) Extracorporeal Photopheresis: Scientific and Technical Considerations for Improving Clinical Management of Patients. J Stem Cell Res Ther 4: 232. doi:10.4172/2157-7633.1000232

Copyright: ( 2014 Garban F, et al. This is an open-access article distributed under the terms of the Creative Commons Attribution License, which permits unrestricted use, distribution, and reproduction in any medium, provided the original author and source are credited. 
made in humans because these studies do not reflect the pathological history of patients, or immune dysregulation during reconstitution, or chronic immunosuppressive drugs for GVHD prevention, or microbial pressure. Moreover, quite often animal studies are based on natural samples that differ from peripheral blood mononuclear cells used in clinical practice, such as mouse spleen cells resulting in an enriched contingent of antigen-presenting cells treated during the ECP procedure. The UVA doses and the process are often far removed from the human treatment. Despite such limitations, animal models of induced autoimmunity have provided a large amount of evidence that ECP may induce suppressor T-cells against auto-reactive cytotoxic T-cells following Freund adjuvant-associated vaccination [7]. These experiments cannot directly be associated to human status because professional antigen presenting cells differ in the mouse and human [8] and immune modulation differs between species as shown, for example, with mesenchymal stromal cells used to modulate GVHD [9]. In conclusion, animal models, which are limited in the study of human GVHD, seem only to be a departure to investigate immunomodulation induced by ECP.

In the human, the best characterized effect of ECP is inducing apoptosis in exposed cells with variable kinetics depending on types and resting status of cells. The lymphocytes die in 24-48 hour or even less time if activated, whereas monocytes are slow to progress toward apoptosis [10-12] and for few days, maintain the properties of differentiation and communication [13]. It appears in GVHD treated by ECP that the clinical benefits result from the processing of these apoptotic cells. A large body of data from many different studies supports the concept of the tolerogenic potential of apoptotic cell infusion [14].

Dendritic cells (DCs) are specialized antigen presenting cells that control immunity, trigger immune response and maintain tolerance [15]. Immature DCs have a high level of endocytic activity, express costimulatory molecules and weakly MHC molecules on their surface, and are poor antigen presenting cells. After activation, they mature and link innate and adaptive immune responses. DCs are environment sensors and as such they receive signals. It has been shown that activated apoptotic T-cells trigger DC maturation [16]. During ECP, a modulation of DC subpopulations and a shift in cytokine profile from Th1 to Th2 have also been observed [17]. Analysis of cytokine profiles post-ECP have demonstrated both a decreased production of immunostimulatory TNF-a and IL-6 [18] whereas immunomodulatory IL-10 and IL-1Ra cytokines increased in patients $[19,20]$. The production of TNF-a, IL-1a, IL-1b, IL-6 and IL-8, detected at a single cell level in monocytes stimulated by LPS of CGvHD patients, are also significantly reduced post-ECP [21]. The presence of apoptotic cells during monocyte activation increases their secretion of immunomodulatory IL-10 and decreases their secretion of the proinflammatory cytokines TNF-a, IL-1 and IL-12 [22]. It was observed that the profile of helper T-cells governs the formation and function of specialized DC subsets
[23]. Thus it seems that ECP induces a modulating environment (at least via apoptotic lymphocytes and altered monocytes) targeting DCs that lead to the control of alloreactivity. GVHD patients have low circulating levels of regulatory T-cells (Treg). The implication of the $\mathrm{CD}^{+} \mathrm{CD}^{2} 5^{+} \mathrm{Foxp}^{+}{ }^{+} \mathrm{T}$-cell population has thus been investigated following ECP. Studies reported that the frequency of T-cells with a regulatory phenotype and suppressive activity is increased during ECP treatment in GVHD patients [12,24] despite the fact that the circulating count does not reach the level observed in healthy donors [25]. This suggests that the induction of Treg cells could add its contribution to the generation of tolerogenic DCs.

For years, it has been demonstrated that during ECP treatment, apoptotic UVA treated-cells lead to the modulation of the inflammatory environment and to the generation of tolerogenic DCs. This impacts T-cell differentiation and subsets (such as Treg). But ECP cannot be reduced to the treatment of lymphocytes and monocytes and an impact on DCs, because granulocytes are also treated [26]. Little is known about their role despite granulocytes represent a major component of the extracorporeal treated bag (20-30\%) in acute GVHD. This introduces a fourth cell population to the understanding of ECP mechanisms.

The level of complexity, the synergy of identified mechanisms and the context of the immunosuppressive environment for GVHD patients make the determination of the upstream event as yet not fully elucidated. For the two remaining main indications of ECP, the situation appears more complex to investigate, with a lack of models or a patient population that is too scarce (cutaneous T-cell lymphomas) or the interaction of numerous immunosuppressive drugs from organ transplantation (as also seen in acute GVHD).

\section{Technical Aspects of ECP: Two-Step System (Apheresis and Cell Therapy Unit) or One-Step System (Integrated System) and Consequences for the Mononuclear Cells Treated}

The integrated system developed and certified by Therakos ${ }^{\mathrm{rax}}$ was available at the end of the 80 s and represents the majority of ECP procedures in the world. The main advantage is a single step system allowing leukocyte collection, immediately followed by cell treatment with psoralen+UVA irradiation in a closed system (Table 1). For both the UVAR-XTS ${ }^{\circledR}$ the last generation Cellex ${ }^{\circledR}$ systems, the energy delivered to mononuclear cells is $1.2 \mathrm{~J} / \mathrm{cm}^{2}$ adjusted to hematocrit value. This one-step technology is limited by the blood volume handled and a poor control on separation conditions such as the use of heparin anticoagulant or the centrifugation compartment breakdown. These blood separation variations introduce final result disparity that is patient dependent since associated to blood mass and blood counts. Moreover this automatic process is more appropriate for adult patients, than for pediatric patients. The FDA approval for an ECP protocol inclusion is restricted by a body weight of at least $40 \mathrm{~kg}$ because of the

\begin{tabular}{|c|c|c|}
\hline & One step system (in line) Cellex ${ }^{\circledR}$ & Two step system (off line) \\
\hline Main principle & $\begin{array}{l}\text { Integrated system: sequences of cell separation-UVA irradiation- } \\
\text { infusion }\end{array}$ & $\begin{array}{c}\text { Mononuclear cell apheresis and separated UVA irradiation of } \\
\text { the total harvested cells }\end{array}$ \\
\hline UVA dose & $1.2 \mathrm{~J} / \mathrm{cm}^{2}$ & $2 \mathrm{~J} / \mathrm{cm}^{2}$ \\
\hline Sample collection for quality control & No & Yes \\
\hline $\mathrm{Nb}$ of Vascular access & One & Two \\
\hline Total duration of course & $1 \mathrm{~h} 30 \mathrm{~min}$ to 2 hours & 3 to 4 hours \\
\hline Pediatric use & Yes but restricted to $>40 \mathrm{~kg}$ & Yes-no restriction \\
\hline Other limitations & Cost & Cell therapy unit required for UVA irradiation \\
\hline
\end{tabular}

Table 1: Practical considerations of the two main photopheresis systems. 
extracorporeal blood volume processed. Only 2 patients -18.5 and 20.5 $\mathrm{kg}$ - were reported [27]. Finally, there is no quality control available on the infused product.

The two-step system (off line French system) was developed 10 years after the one step system with the aim to standardize leukapheresis collection and UVA-irradiation (the energy delivered to mononuclear cells were setup at $2 \mathrm{~J} / \mathrm{cm}^{2}$ adjusted to hematocrit value) with an independent technology (i.e Macogenic ${ }^{\circledR}$ or UVA Pit system ${ }^{\mathrm{Tx}}$ ) (Table 1) [28]. Thus, the collection efficiency which separate up to $55 \%$ of the handled cells is compatible with standardization and quality control on nuclear cells treated, as on the buffy coat hematocrit. Since the oldest apheresis system COBE Spectra ${ }^{\circledR}$, new cell separators are approved to collect large amount of mononuclear cell in either adult or pediatric patients [29] with major inconvenience of double vascular puncture.

Comparison between one-step and two-step system appears complicated. The only comparative study published concerned obsolete equipment [28]. In this study, the linear relationship between lymphocytes counts in the patient blood and in the buffy-coat collected was demonstrated as the key parameter for the cells treated amount estimation. Since, all the technological developments of the one-step system were based on improving the collection efficiency and reducing the blood volume processed. Despite cell separation efficiency from the Cellex ${ }^{\mathbb{B}}$ system [30] compared to the standard apheresis is close, the total amount of lymphocytes treated per individual course remains higher with the two-step system since a bigger blood volume is processed. Moreover, if lymphocytes count is easy to measure, no correlation could be made between (estimated) lymphocytes treated and clinical responses. When measured in the two step system, the others cells treated monocytes and granulocytes could be estimated respectively at $24 \%$ and $15 \%$ [26], introducing new possible parameters for the clinical management. In the absence of reliable management parameters, either quality control on the processed cells either clinically relevant marker, schedules of treatment remain empiric. Based on the total amount of lymphocytes treated, the short duration of procedure, the recent trials in GVHD with the Therakos ${ }^{\text {Tw }}$ Cellex $^{\circledR}$ system report the use of repeated numerous courses (10 to 60 ) over 1 to 17 months [27,31].

These technical considerations could play a role for the design of trials since more efficient courses may lead to a reduction of courses and to a reduction and costs. The challenge is to determine what is the optimal cells amount to treat, while optimizing mononuclear cells harvested by unit of time.

\section{Patient Management, From Indications to the Schedule of ECP Courses: Clinical Features}

More than twenty five years after its first described use and hundreds of publications, ECP is today a recognized and effective therapeutic option in CTCL, GVHD and solid transplantation rejection. We aim to present the different indications for ECP, focusing on the benefits and limitations that still remain.

\section{Cutaneous T-cell lymphoma and other $\mathrm{T}$-cell malignancies with circulating clones}

Since the first publication by Edelson [1], ECP has become the first-line recommended treatment of CTCL, either from erythrodermic mycosis fungoides or Sezary syndrome, with disseminated disease defined by the presence of a circulating clone [32]. In these disseminated erythrodermic CTCL, the median response reported is 63\% (range 3080\%) [33]. The schedule of treatment is now well-standardized with an intensive induction phase consisting of two consecutive days every two weeks followed by observation of a response in maintenance/ sustaining phase. Additionally, a potential additional role of INFalpha, or immunomodulators, combined with ECP has been proposed in various types of CTCL [34]. Based on the observation that in CTCL, the circulating clone could be targeted by the ECP procedure, in 2012 we reported ECP's efficacy for refractory or relapsing peripheral T-cell lymphomas with circulating clone and T-cell large granular lymphocyte leukemia in a Sezary's lymphoma-inspired protocol [35]. We showed that ECP is able to elicit prolonged complete responses, and that targeting only the circulating clone could constitute an effective therapeutic approach in these indications with poor outcomes. Obviously, prospective trials are needed to confirm these results, with the limitation of the scarcity of these pathologies.

\section{Graft versus host disease: more in chronic than in acute GVHD?}

ECP's place in cGVHD treatment strategy has been explored for almost twenty years, as an alternative to immunosuppressive drugs and irradiation, both complicated by an increased risk of infections. With the lack of randomized controlled trials, ECP results cannot be evaluated and ranked against other second-line treatment of cGVHD. Moreover, in cGVHD, clinical trials encounter difficulties in defining the response. Individual organ assessment has been widely used since it is easy to investigate with routine biological parameters. Nevertheless these data are difficult to connect with clinical data reproducibly and do not reflect the heterogeneity of an organ's response to treatment. Global scoring of GVHD with National Institutes of Health Consensus for measuring response could be helpful [36] but is currently more appropriate for prospective studies. In GVHD patients, ECP is almost always associated at least with a corticosteroid treatment, so the reduction of immunosuppressive-associated therapies seems to be a more reliable global assessment. Despite these difficulties, ECP demonstrates significant results in cutaneous, gastrointestinal, hepatic, oral, ocular or musculoskeletal cGVHD (recent meta-analysis by AbuDalle, et al.) in both, pediatric or adult patients [37]. The decrease of corticosteroids has also been reported as significant and consistent criteria for ECP response. Little is known about using ECP as first-line treatment of cGVHD, but we have observed some encouraging results in skin or oral cGVHD (Garban et al., unpublished data). Lung cGVHD remains a controversial indication of ECP, and needs to be investigated, probably as chronic lung transplant dysfunction in combination with immunosuppression.

In aGVHD, steroid treatment of 1 to $2 \mathrm{mg} / \mathrm{kg} /$ day is a standardized and validated first-line treatment [38]. The second line therapeutic strategy remains controversial due to the lack of randomized prospective trials. ECP is one of these strategies. Much work on ECP is composed of retrospective studies whereas only a few observational prospective studies are reported that integrate patients with aGVHD (often mixed to heterogeneous population including cGVHD patients). Only one randomized prospective trial has demonstrated interesting clinical results in aGVHD [5]. Two recent synthetic analyses sought to more precisely define the efficacy of ECP in aGVHD. A meta-analysis based on nine relevant prospective studies showed a pooled overall response rate of 0.69 (skin 0.84 , gut 0.65 , liver 0.65) [37]. A Recent review reports similar results in response with an impact of ECP response on overall survival in multivariate analysis that is much more meaningful for clinical practice [39]. We also have to consider that the complexity of using and evaluating ECP in aGVHD is related to the delayed onset of ECP, delayed action and the necessity of combined immunosuppression. 
Then, considering that ECP is a validated indication of GVHD treatment, the ECP schedule courses question remains. Considering reported studies, the modality of ECP treatment varied from one center to another. Most of the clinical reports used numerous courses from the UVAR-XTS ${ }^{\circledR}$ system which is progressively replaced by the Cellex ${ }^{\circledR}$ system (more efficient in terms of cells treatment) that still lack evaluation. Regarding the recent studies with the Cellex ${ }^{\circledR}$ and the two-step system, an intensive or induction phase of 6 to 10 courses (over one month) is necessary before observing clinical response or defining a status of no-responder. In responding patients, the maintenance therapy appeared to be necessary to achieve the decrease of immunosupressive drugs, from 10 courses with the two step system to 60 with Cellex ${ }^{\circledR}$ and even more with the UVA XTS ${ }^{\circledR}$.

\section{Solid organ transplantation: from rejection treatment to immunological disorders management}

In parallel to ECP treatment for GVHD, ECP has been developed for lung and heart transplantation and is characterized by the lack substitute treatment in case of transplant rejection and failure [40,41]. In heart transplantation, the success in prevention or treatment of transplant rejection from ECP described at the end of the 90 's is counterbalanced by the progress in managing immunosuppressive drugs. However, in lung transplantation, where chronic rejection appears more complex, with less sensitivity to drug immunosuppression and more infectious complications, ECP could be a preferred choice as combination treatment. Since 1995, numerous retrospective studies have shown promise for ECP in chronic lung allograft dysfunction (CLAD)/Bronchiolitis Obliterans Syndrome (BOS) with sustained efficacy on pulmonary function and even discontinuation of some immunosuppressive drugs [42]. A recent retrospective study suggests that ECP may show effectiveness in patients exhibiting neutrophilic CLAD but not in rapid decliner and non-neutrophilic CLAD [43]. Considering the clinical results acquired for cGVHD and chronic transplant rejection, experiments with ECP in numerous immunological disorders have had some encouraging results in small series or in case reports [44]. The more relevant pathologies are Crohn's disease, multiple sclerosis, diabetes mellitus, and cutaneous disorders.

\section{Conclusion}

Based on data in the literature on well-defined indications (forms of cGVHD, CTCL, chronic organ rejection), ECP appears to be a treatment with significant advantage in risk-benefit ratio notably because of its efficacy and its immunomodulatory role without reported immunosuppression. Indeed, ECP seems to be safe in these immunodepressed populations with low rates of grade 3-4 events and particularly the absence of infectious complications [37]. For other indications such as aGVHD, peripheral $\mathrm{T}$ lymphomas with circulating clones, some immune disorders, there is a potent benefit that should be considered with other available treatments. Despite these clinical successes, we have to consider confounding factors in clinical trials that may temper the benefit interpretation for a given indication: 1) the ECP procedures: one step versus the two-step system. While the majority of trials used UVAR XTS ${ }^{\circledR}$ system from Therakos ${ }^{\mathrm{TM}}$, the Cellex ${ }^{\circledR}$ system use expand and has not totally been evaluated; 2) the schedule of courses: induction+maintenance versus courses with periodic interval; 3) the associated treatment in the case of immunosuppression; 4) the different assessments of the response; 5) and, in case of response, the duration of response is not frequently reported. The other major point, is the absence of economic evaluation including the whole cost of treatment (for either one- or two-step methods) compared to other therapeutic options.
Beyond the various technical aspects, the differences in quantity and quality of treated cells for the one step and the two step systems, it is not possible to find a minimal common schedule between centers. Indeed there are substantial variations between clinical practices, irrespective of the system for parameters such as frequency, interruptions and evaluations of responses whereas the clinical trial reports indicate only the total number of proceedings.

In conclusion, it is our opinion that for clinical practice, the key messages when considering ECP as routine treatment are: the indication for use in cGVHD is skin, oral-ocular, or gut involvement, as soon as possible in second or third-line. For aGVHD, ECP is more efficient with early onset and an intensive schedule (2-3 courses a week); skin and gut aGVHD are the best responding organs, but there are alternative treatments such as monoclonal antibodies [44]. Both in acute and chronic GVHD, lack of response after 6-8 courses should be considered resistant GVHD except in systemic sclerosis and perhaps in lung GVHD. ECP could be proposed for chronic transplant dysfunction in lung and heart, but the optimal duration of ECP treatment remains unknown. All other indications could be investigated by entering patients in clinical trials.

\section{References}

1. Edelson R, Berger C, Gasparro F, Jegasothy B, Heald P, et al. (1987) Treatment of cutaneous T-cell lymphoma by extracorporeal photochemotherapy. Preliminary results. N Engl J Med 316: 297-303. [PubMed]

2. Costanzo-Nordin MR, Hubbell EA, O'Sullivan EJ, Johnson MR, Mullen GM, et al. (1992) Photopheresis versus corticosteroids in the therapy of heart transplant rejection. Preliminary clinical report. Circulation 86: 242-250. [PubMed]

3. Andreu G, Achkar A, Couetil JP, Guillemain R, Heshmati F, et al. (1995) Extracorporeal photochemotherapy treatment for acute lung rejection episode. J Heart Lung Transplant 14: 793-796. [PubMed]

4. Laurin D, Hannani D, Pernollet M, Moine A, Plumas J, et al. (2010) Immunomonitoring of graft-versus-host minor histocompatibility antigen correlates with graft-versus-host disease and absence of relapse after graft. Transfusion 50: 418-428. [PubMed]

5. Flowers ME, Apperley JF, van Besien K, Elmaagacli A, Grigg A, et al. (2008) A multicenter prospective phase 2 randomized study of extracorporeal photopheresis for treatment of chronic graft-versus-host disease. Blood 112 : 2667-2674. [PubMed]

6. Suchin KR, Cassin M, Washko R, Nahass G, Berkson M, et al. (1999) Extracorporeal photochemotherapy does not suppress $\mathrm{T}$ - or B-cell responses to novel or recall antigens. Journal of the American Academy of Dermatology 41: 980-986.

7. Ben-Nun A, Wekerle H, Cohen IR (1981) Vaccination against autoimmune encephalomyelitis with T-lymphocyte line cells reactive against myelin basic protein. Nature 292: 60-61. [PubMed]

8. Hancock DG, Guy TV, Shklovskaya E, Fazekas de St Groth B (2013) Experimental models to investigate the function of dendritic cell subsets: challenges and implications. Clinical and experimental immunology 171: 147154. [PubMed]

9. Lawitschka A, Ball L, Peters C (2012) Nonpharmacologic treatment of chronic graft-versus-host disease in children and adolescents. Biol Blood Marrow Transplant 18: S74-81. [PubMed]

10. Enomoto DN, Schellekens PT, Yong SL, Ten Berge IJ, Mekkes JR, et al. (1997) Extracorporeal photochemotherapy (photopheresis) induces apoptosis in lymphocytes: a possible mechanism of action of PUVA therapy. Photochem Photobiol 65: 177-180. [PubMed]

11. Heng AE, Sauvezie B, Genestier L, Demeocq F, Dosgilbert A, et al. (2003) PUVA apoptotic response in activated and resting human lymphocytes. Transfus Apher Sci 28: 43-50. [PubMed]

12. Lamioni A, Parisi F, Isacchi G, Giorda E, Di Cesare S, et al. (2005) The immunological effects of extracorporeal photopheresis unraveled: induction of tolerogenic dendritic cells in vitro and regulatory $T$ cells in vivo. Transplantation 79: 846-850. [PubMed] 
Citation: Garban F, Makowski C, Carras S, Drillat P, Gressin R, et al. (2014) Extracorporeal Photopheresis: Scientific and Technical Considerations for Improving Clinical Management of Patients. J Stem Cell Res Ther 4: 232. doi:10.4172/2157-7633.1000232

13. Setterblad N, Garban F, Weigl R, Assier E, Drillat P, et al. (2008) Extracorporeal photophoresis increases sensitivity of monocytes from patients with graftversus-host disease to HLA-DR-mediated cell death. Transfusion 48: 169-177. [PubMed]

14. Albert ML (2004) Death-defying immunity: do apoptotic cells influence antigen processing and presentation? Nat Rev Immunol 4: 223-231. [PubMed]

15. Steinman RM (2012) Decisions about dendritic cells: past, present, and future. Annu Rev Immunol 30: 1-22. [PubMed]

16. Johansson U, Walther-Jallow L, Smed-Sorensen A, Spetz AL (2007) Triggering of dendritic cell responses after exposure to activated, but not resting, apoptotic PBMCs. J Immunol 179: 1711-1720. [PubMed]

17. Gorgun G, Miller KB, Foss FM (2002) Immunologic mechanisms of extracorporeal photochemotherapy in chronic graft-versus-host disease. Blood 100: 941-947. [PubMed]

18. Neuner P, Charvat B, Knobler R, Kirnbauer R, Schwarz A, et al. (1994) Cytokine release by peripheral blood mononuclear cells is affected by 8 -methoxypsoralen plus UV-A. Photochem Photobiol 59: 182-188. [PubMed]

19. Fimiani M, Di Renzo M, Rubegni P (2004) Mechanism of action of extracorporeal photochemotherapy in chronic graft-versus-host disease. Br J Dermatol 150: 1055-1060. [PubMed]

20. Vowels BR, Cassin M, Boufal MH, Walsh LJ, Rook AH (1992) Extracorporeal photochemotherapy induces the production of tumor necrosis factor-alpha by monocytes: implications for the treatment of cutaneous T-cell lymphoma and systemic sclerosis. J Invest Dermatol 98: 686-692. [PubMed]

21. Bladon J, Taylor PC (2005) Lymphocytes treated by extracorporeal photopheresis can down-regulate cytokine production in untreated monocytes. Photodermatology, photoimmunology \& photomedicine 21: 293-302.

22. Voll RE, Herrmann M, Roth EA, Stach C, Kalden JR, et al. (1997) Immunosuppressive effects of apoptotic cells. Nature 390: 350-351. [PubMed]

23. Alonso MN, Wong MT, Zhang AL, Winer D, Suhoski MM, et al. (2011) T(H)1, $T(H) 2$, and $T(H) 17$ cells instruct monocytes to differentiate into specialized dendritic cell subsets. Blood 118: 3311-3320. [PubMed]

24. Biagi E, Di Biaso I, Leoni V, Gaipa G, Rossi V, et al. (2007) Extracorporeal photochemotherapy is accompanied by increasing levels of circulating CD4+CD25+GITR+Foxp3+CD62L+ functional regulatory T-cells in patients with graft-versus-host disease. Transplantation 84: 31-39. [PubMed]

25. Schmitt S, Johnson TS, Karakhanova S, Naher H, Mahnke K, et al. (2009) Extracorporeal photophoresis augments function of CD4+CD25+FoxP3+ regulatory $T$ cells by triggering adenosine production. Transplantation 88: 411416. [PubMed]

26. Garban F, Drillat P, Makowski C, Jacob MC, Richard MJ, et al. (2005) Extracorporeal chemophototherapy for the treatment of graft-versus-host disease: hematologic consequences of short-term, intensive courses. Haematologica 90: 1096-1101. [PubMed]

27. Rangarajan HG, Punzalan RC, Camitta BM, Talano JA (2013) The use of novel Therakos Cellex(R) for extracorporeal photopheresis in treatment of graft-versus-host disease in paediatric patients. $\mathrm{Br} \mathrm{J}$ Haematol 163: 357-364. [PubMed]

28. Andreu G, Leon A, Heshmati F, Tod M, Menkes CJ, et al. (1994) Extracorporeal photochemotherapy: evaluation of two techniques and use in connective tissue disorders. Transfusion science 15: 443-454. [PubMed]

29. Schulz M, Bialleck H, Thorausch K, Bug G, Dunzinger U, et al. (2014) Unstimulated leukapheresis in patients and donors: comparison of two apheresis systems. Transfusion 54: 1622-1629. [PubMed]
30. Liu C, Shah K, Dynis M, Eby CS, Grossman BJ (2013) Linear relationship between lymphocyte counts in peripheral blood and buffy coat collected during extracorporeal photopheresis. Transfusion 53: 2635-2643. [PubMed]

31. Ussowicz M, Musial J, Mielcarek M, Tomaszewska A, Nasilowska-Adamska B, et al. (2013) Steroid-sparing effect of extracorporeal photopheresis in the therapy of graft-versus-host disease after allogeneic hematopoietic stem cell transplantation. Transplant Proc 45: 3375-3380. [PubMed]

32. Andreu-Ullrich H (2014) Miscellaneous indications for extracorporeal photochemotherapy (ECP). Transfus Apher Sci 50: 363-369. [PubMed]

33. Quaglino P, Knobler R, Fierro MT, Savoia P, Marra E, et al. (2013) Extracorporeal photopheresis for the treatment of erythrodermic cutaneous T-cell lymphoma: a single center clinical experience with long-term follow-up data and a brief overview of the literature. Int J Dermatol 52: 1308-1318. [PubMed]

34. Zic JA (2012) Photopheresis in the treatment of cutaneous T-cell lymphoma: current status. Curr Opin Oncol 24: S1-10. [PubMed]

35. Garban F, Carras S, Drillat P, Jacob MC, Fabre B, et al. (2012) Extracorporea photopheresis as a curative treatment strategy in non epidermotropic T-cell lymphoma and large granular lymphocyte leukemia. Ann Oncol 23: 2386-2390. [PubMed]

36. Pavletic SZ, Martin P, Lee SJ, Mitchell S, Jacobsohn D, et al. (2006) Measuring therapeutic response in chronic graft-versus-host disease: National Institutes of Health Consensus Development Project on Criteria for Clinical Trials in Chronic Graft-versus-Host Disease: IV. Response Criteria Working Group report. Biol Blood Marrow Transplant 12: 252-266. [PubMed]

37. Abu-Dalle I, Reljic T, Nishihori T, Antar A, Bazarbachi A, et al. (2014) Extracorporeal Photopheresis in Steroid-Refractory Acute or Chronic Graftversus-Host Disease: Results of a Systematic Review of Prospective Studies. Biol Blood Marrow Transplant. [PubMed]

38. Martin PJ, Rizzo JD, Wingard JR, Ballen K, Curtin PT, et al. (2012) Firstand second-line systemic treatment of acute graft-versus-host disease: recommendations of the American Society of Blood and Marrow Transplantation. Biol Blood Marrow Transplant 18: 1150-1163. [PubMed]

39. Das-Gupta E, Dignan F, Shaw B, Raj K, Malladi R, et al. (2014) Extracorporeal photopheresis for treatment of adults and children with acute GVHD: UK consensus statement and review of published literature. Bone marrow transplant. [PubMed]

40. Barr ML, Meiser BM, Eisen HJ, Roberts RF, Livi U, et al. (1998) Photopheresis for the prevention of rejection in cardiac transplantation. Photopheresis Transplantation Study Group. The New England journal of medicine 339: 1744 1751.

41. Dall'Amico R, Livi U, Milano A, Montini G, Andreetta B, et al. (1995) Extracorporeal photochemotherapy as adjuvant treatment of heart transplant recipients with recurrent rejection. Transplantation 60: 45-49. [PubMed]

42. Jaksch P, Knobler R (2014) ECP and solid organ transplantation. Transfus Apher Sci 50: 358-362. [PubMed]

43. Greer M, Dierich M, De Wall C, Suhling H, Rademacher J, et al. (2013) Phenotyping established chronic lung allograft dysfunction predicts extracorporeal photopheresis response in lung transplant patients. Am J Transplant 13: 911-918. [PubMed]

44. Meunier M, Bulabois CE, Thiebaut-Bertrand A, Itzykson R, Carre M, et al. (2014) Alemtuzumab for Severe Steroid Refractory Gastro-Intestinal Acute GVHD. Biol Blood Marrow Transplant 20: 1451-1454. [PubMed] 